\title{
MIRÓ Y MIDRASH: EL CASO DE FIGURAS DE LA PASIÓN DEL SEÑOR
}

\author{
Al Profesor \\ Francisco Márquez Villanueva, \\ mi maestro en todo lo mironiano
}

\section{Kevin S. LARSEN}

Universidad de Wyoming

\section{RESUMEN}

En Figuras de la Pasión del Señor, Miró se pone a reimaginar las historias bíblicas -al igual que otras muchas extra bíblicas- en torno a la vida y la muerte de Jesucristo. Crea y recrea un medio ambiente, si no el medio ambiente, de la primera época cristiana, proponiendo una plétora de posibles narrativas. El novelista se esfuerza por ir más allá de la mera ficción histórica para lograr una autenticidad y una verosimilitud de la Escritura misma. Miró escribe un midrash, una modalidad sumamente creatriz, al principio rabínica, que ahora encontramos en muchas obras literarias, escritas tanto por judíos como por gentiles. Tal tratamiento de «lo viejo y lo santo», tal y como pudiera haber sido, forzosamente llega a ser una poesis, eso es, la creación poética, hasta un poema en el sentido más elemental.

Palabras clave: midrash, Biblia, Pasión de Jesucristo, poesis, judíos, Fray Antonio de Guevara, Mel Gibson, Sor Ana Catalina Emmerich, Salmo 137 (136), Cervantes.

\section{ABSTRACT}

In Figuras de la Pasión del Señor, Miró sets himself to re imagine biblical stories -not to mention some extra biblical ones- set in and around the life and death of Jesus Christ. He creates and recreates an atmosphere, if not the atmosphere, of the first Christian era, proposing a plethora of possible narratives. The novelist strives to move beyond mere historical fiction to achieve an authenticity and a verisimilitude of the Scripture itself. Miró writes a midrash, a vibrantly creative modality, originally rabbinical, that now we encounter in numerous literary works, written by Jews and Gentiles alike. 
This treatment of «lo viejo y lo santo» as it might have been of necessity becomes a poesis, that is, poetic creation, even a poem in the most basic sense.

Key words: midrash, Bible, Passion of Jesus Christ, poesis, Jews, Fray Antonio de Guevara, Mel Gibson, Sor Ana Catalina Emmerich, Psalm 137 (136), Cervantes.

En una carta que dirige a Eduardo Irles, Miró explica su voluntad de investigar para después escribir su novela sobre la Pasión de Jesucristo: esta obra nace «no por afán de primitivismo como procedimiento y fórmula de arte, no por intenciones exegéticas ni por fervores apologéticos ni sectarios, sino por ingenuidad, por ansia ingénua, es decir, inculcada en mi sangre y en mis huesos desde la niñez, de mirar de cerca el horizonte cristiano, reconstruyendo lo que no nos decían los textos directos y sagrados» (citado por Ramos 1969, pág. 11). En su artículo «La conciencia mesiánica en Jesús», el novelista alicantino centra sus esfuerzos principalmente en «reconstituir» la niñez y la juventud del Nazareno, aunque a la luz de su futura misión y Pasión. En Figuras, Miró toma un rumbo bastante parecido, aunque mucho más amplio. ${ }^{1}$ Se pone a reimaginar, y luego a reescribir, las historias narradas -al igual que otras no narradas- en la Santa Biblia, recreando el medio ambiente de la época que fue origen de la cristiandad. Es un afán, tal como dice don Gabriel, no de primitivismo, sino de alguna forma de poder presenciar la Pasión, haciéndosela presente a sí mismo y a sus lectores. Tal modalidad exige que el autor construya y reconstruya, novelando aspectos de la Sagrada Escritura, lo que le brinda casi un sinfín de posibilidades narrativas. Sin embargo, Miró se esfuerza por ir más allá de la mera ficción histórica para lograr una autenticidad y una verosimilitud de la Escritura misma (ver Macdonald 2002, págs. 81-96).

Al contextualizar su novela de acuerdo con la textura de la Biblia, el novelista llega a una poesis, a la creación poética, a un «poema» en el sentido más elemental de la palabra; esto es: algo creado por medio del lenguaje. No quiere decir que Figuras sea explícitamente poesía, aunque sí se hace participante de una larguísima tradición poética. Ha llegado a ser casi un truísmo de la crítica señalar lo poético del discurso mironiano e insistir en Miró como poeta en prosa. Pero no resulta ocioso seguir matizando tal visión. ${ }^{2}$ Por mi parte, propongo que Miró se involucra en un género literario muy antiguo, y al mismo

1. Cito aquí por la edición de la Biblioteca Nueva (Obras completas). Las demás referencias a «La conciencia mesiánica...» y a Figuras serán incluídas parentéticamente en el texto del trabajo según esta misma edición. Agradezco a Martha Muciño de Shumway, mi colega del Instituto Ometeca, su lectura crítica de este trabajo, igual que sus muchas buenas sugerencias para mejorarlo.

2. Entre los muchísimos estudios de la prosa poética y lírica de Miró, ver Guillén, Lozano Marco y Prieto de Paula. 
tiempo de suma modernidad, que se llama midrash: este fenómeno principalmente rabínico consiste en una historia o narración sobre algún incidente o personaje bíblico, detallando, «completando» el texto original, según pudiera haber sido. De acuerdo con tales principios (y fines), en manos de Miró o de cualquier otro escritor que lanza su obra en esta serie tan diversa, la novela midrashica forzosamente se incorpora como algo en sí poético. Pero en esta novela, Miró utiliza solamente una vez la palabra midrash. Al describir una procesión, alude al «Hâkân, que dirige a los soferim o escribas, levitas y seglares, teósofos, hermeneutas, exegetas, cuyos estudios y escolios, componen la Mischna, la Midras, el Hagada» (pág. 1.291). ${ }^{3}$ Sin embargo, a lo largo de Figuras se encuentran muchos aspectos del midrash, desde los epígrafes que son versículos de la Escritura y que dan enfoque a cada capítulo, hasta los pasajes de la Escritura intercalados y glosados, ora directa, ora más oblicuamente, en la narrativa. Existen historias enteras de la Biblia que han estado incluidas en el texto de Figuras, aparentemente para servir como caja de resonancia o aun como trampolín para lanzar otra narración. Otra palabra que Miró usa en este mismo pasaje de Figuras, así como en otro lugar de la novela (pág. 1.251), es hagada=haggadah, que quiere decir algo que se cuenta, saber popular, tradición o historia, y que puede servir como sinónimo de midrash.

El desarrollo de los midrashim, antiguamente o en épocas más recientes, no constituye «relativismo» alguno, ya que el texto bíblico sigue considerándose sagrado: sólo que en él existe latente una legión de posibles variantes, las que quizá sean contradictorias entre sí, pero que a su vez pueden llegar a ser Escritura. En la carta a Irles, Miró niega su intención explícitamente exegética, pero el midrash en su sentido más esencial comprende una suerte de exégesis, aunque de un estilo no inmediatamente reconocible para todos los cristianos. Al proponer a Miró como midrashista en Figuras, de ninguna manera quisiera sugerir que él fuera menos cristiano, ni que se hiciera «judaizante»; sólo que su arte se dirige por otros cauces muy antiguos, vertiendo su vino viejo en odres viejos, aunque del mismo modo renovando tanto el vino como el vaso. A ello se le incorpora la imagen de Miró como creyente liberal, de una mente abierta a la novedad. En ello sus contrafiguras serían don Magín (cuyo nombre lo dice todo) y quizá el obispo leproso de las novelas de Oleza,

3. No entiendo por qué la palabra Midras viene aquí como femenina y sin la $h$ posterior, porque se deletrea con shin, en vez de sin. El hagada se transcribe más bien como la haggadah, ya que se escribe en hebreo con doble gimel y luego con he al final. Además, es un sustantivo femenino y el acento cae en la última sílaba, no en la primera. Consta que por ahora lo importante es aprehender la hermenéutica mironiana, en vez de demorarnos en detalles relativamente menores. 
todos frente al Padre Bellod, encarnación de la iglesia archiconservadora, si no inquisitorial.

A través de las generaciones han sido escritas muchísimas obras que evidencian importantes aspectos del midrash. Desde Chaucer, Cervantes y Milton, hasta Proust, Mann y Borges, una larga serie de los gentiles, amén de los hebreos, se han valido de las casi infinitas posibilidades literarias de lo que no decían directamente los textos sagrados, llegando a reelaborar la narrativa sagrada y a reescribir la Escritura. Los autores de los libros del Nuevo Testamento y después de ellos, otros escritores más bien profanos, han señalado la comunicación intertestamental, ya que algunas de las mismas modalidades empleadas por los evangelistas han sido utilizadas también por los que escriben/compilan los varios libros de la Escritura Hebrea. Es que los que escribieron los libros del Nuevo Testamento, igual que muchos textos no canónicos, participan en las mismas tradiciones, valiéndose de los mismos temas y técnicas que emplean sus antecesores. Hasta los tiempos más recientes, los sucesores, igual que los contemporáneos rabínicos de los escritores protocristianos, han desarrollado tales maneras de aprehender y de imaginar lo que es y lo que puede ser la Escritura. ${ }^{4}$

Es verdad que Miró no escribe tendenciosamente, ni con fines sectarios, sino con propósitos estéticos, reconfigurando las historias según su propia visión poemática. Ha llegado a ser otro tema medio trillado de la crítica el indicar que el novelista ha creado una serie de viñetas, unas «estampas» relativamente independientes. Pero las figuras diversas de esta novela epónima llegan a contextualizarse en una compañía creíble y coherente, mientras que las varias escenas se compaginan en un escenario inteligible (ver Baeza págs. xix-xxi). Miró no se dispone a crear una ficción histórica ni una historia novelada, sino a realizar, a reivindicar en su propia novelística, historias sudedidas en los últimos días de Jesús Nazareno. Bien sabemos, por las investigaciones de Vicente Ramos, Ian Macdonald, Francisco Márquez Villanueva, James Airozo, John R. Kirk y otros críticos que siguen comentando esta novela, que en Figuras, Miró se distingue como un dedicado discípulo, valiéndose como

4. Sobre el uso del midrash en el Nuevo Testamento, ver Gertner págs. 267-92; Wright pág. 20 et passim; Sandmel págs. 105-22. Una bibliografía muy reducida del midrash podría incluir los siguientes tomos: Hartman y Budick, eds. 1986; Fishbane 1998; Schwartz 1998; Kugel 1994; Neusner 1983 y 1986; Handelman 1982. Por curiosidad, al comenzar este trabajo, emprendí también una indagación electrónica por medio de MLA International Bibliography, para ver cuántas referencias podría localizar en cuanto a midrash. Salieron a la pantalla más de 130, las que trataban, entre otras formas de bellas letras, de diversos, y para mí, impensados cuentos, novelas, poesías y películas que cobran relieve como midrashim. 
esteta y como estudioso de una plétora de fuentes, desde los mismos textos sagrados de la tradición judeo-cristiana, hasta los tomos de investigación y de la «alta crítica». ${ }^{5}$ Cabe recordar en este contexto que el término midrash quiere decir investigación o estudio, con su raíz en darash. Pero aquí no se trata exclusivamente de los detalles que Miró ha sabido dominar, los que sabemos que son muchísimos, sino de una cuestión de mentalidad y de metodología.

El novelista respeta plenamente la autoridad de los evangelistas, pero entiende también lo que es la Escritura, que está escrita de acuerdo con el lenguaje y la perspectiva falibles de los seres humanos, aunque sin dejar de ser historias inspiradas. Asimismo, Miró parece comprender que estos mismos escritores del Nuevo Testamento a su vez son midrashistas. Al novelista alicantino le hubiera sentado bien lo que dijo su amigo, Miguel de Unamuno, quien en San Manuel Bueno, mártir (1930) caracteriza la Sagrada Escritura como una «divina novela». Subraya la idea de que «la novela es la más íntima historia, la más verdadera, por lo que no me explico que haya quien se indigne de que se llama novela al Evangelio, lo que es elevarle, en realidad, sobre un cronicón cualquiera» (pág. 1.154). Ni Miró ni Unamuno aceptan la Biblical inerrancy, o sea, la infalibilidad textual. Por su parte, Miró reconoce los poderes, al igual que las naturales imperfecciones, del lenguaje humano, especialmente cuando son contrastados con el plenipotente Verbo Divino. Miró ofrece sus propios escritos, no para reemplazar la Sagrada Escritura, sino para verificarla. Desarrolla su texto para poder «mirar de cerca el horizonte cristiano». Sin embargo, lo que configura en su tomo sobre la Pasión es una narrativa en su esencia más bien judía, pero en la cúspide de la era cristiana. Comunica en Figuras lo que nombra como la «emoción del primer hombre pisando las piedras del primer templo cristiano...» (pág. 1.258), pero describe el ámbito del Segundo Templo de Jerusalén, el de Herodes, donde lo cristiano todavía resulta en función del culto judaico.

Otro presupuesto de la crítica es que Miró pinta el paisaje del Oriente Medio al describir el Levante español. Pero se presenta también el inverso, ya que sus descripciones de Tierra Santa recapitulan muchos aspectos de lo

5. Entre otros estudios de las fuentes mironianas, ver Ramos 1964; Macdonald 1975, 1990, págs. 49-61, y 2002, págs. 81-96; Márquez Villanueva 1990, págs. 17-40, y 1968, págs. 45-46; Airozo 1987, págs. 361-70, y 1984, págs. 212-66; Kirk 1979, págs. 66-83, y 1976. Por su parte, Baeza hace patente que Miró, mientras escribía, «nunca hubo de utilizar el sistema de papeletas o apuntes que emplean la mayoría de los escritores... Palabras y datos, expresión o información, Miró se asimilaba siempre la materia prima de su obra, y sólo cuando se la había integrado de tal modo en sus adentros, en la sensibilidad y en la memoria, que formaba parte de sí propio, pasaba al trabajo de creación» (pág. xii). 
alicantino y de lo español. En «Lo viejo y lo santo en manos de ahora» Miró mismo reconoce tal verdad, de acuerdo con Unamuno, Georges Pillement y otros contemporáneos suyos, quienes afirman que Alicante es la Palestina de Figuras, y viceversa. Al mismo tiempo, Miró indica que hay grandes diferencias que tienen que tomarse en cuenta: «en Levante, todo es levantino; y, en Palestina, todo es únicamente de allí» (págs. 314-16). Pero no por ello deja de repercutir una tierra en la otra, y por decirlo así, que se hacen midrash, una de la otra. Por supuesto, cualquier paisaje, o cualquier pasaje literario, tiene por necesidad que existir en función de la imaginación del autor, así como de su observación. Cabe decir que Miró participa de la voluntad orientalista expresada por autores como Chateaubriand, Flaubert y Renan, entre otros que tanto influyeron en su novelística. A propósito, Márquez Villanueva señala el fuerte contraste entre Miró, a quien caracteriza como un incomprendido, un aislado, un desdeñado y hasta un «santo laico» (1990, págs. 28-33), y Fray Antonio de Guevara (1480?-1545), autor de varios comentarios bastante populares sobre la Pasión. En Monte Calvario y Las siete palabras

Guevara ha hispanizado la acción en forma sistemática; a la inversa de los noveladores modernos de la Pasión (recordemos a Miró) no se interesa para nada en su orientalismo exótico. Le impulsa, por el contrario, un claro afán de acercarse y captar al lector por la vía de lo más familiar y cuotidiano. Aquella Jerusalén es en realidad Toledo o Salamanca o Valladolid (Márquez Villanueva 1968, pág. 45).

Como siempre, Márquez Villanueva acierta en sus opiniones sobre el arte mironiano, igual que sobre el de Guevara. Sólo propongo en el caso de Miró una pequeña matización para calificar, al menos en parte, lo que Ricardo Baeza llama «su aleación de lo antiguo y lo moderno; el sentimiento, a la vez, de lo remoto y lo cercano; la nobleza y la profundidad de lo antiguo, que nos ahonda las raíces en el pasado, unidas al ímpetu y la gracia y la susceptibilidad de lo moderno» (pág. xiv). Siendo español, Miró y sus obras pasan por los cauces del orientalismo tradicional, pero sólo en cierto grado, escapándose luego para desempeñar otros papeles, algunos de éstos algo más semejantes a los desarrollados por Guevara. Según explica Edward Said, los escitores nativos de España, a diferencia de sus contrafiguras francesas e inglesas, no suelen representar un orientalismo tan exagerado. Aquéllos no se enfocan (al menos no al nivel de los otros europeos) en el exotismo cultural y étnico de Oriente y sus gentes (ver Orientalism). Esto sucede porque en el contexto peninsular, lo exótico resulta menos extraño, por ser menos extranjero: efectivamente, el otro es el natural. A despecho de las pretensiones castizas e inquisitoriales, las «razas» de Iberia continúan siendo múltiples: siempre es posible que 
sobrevivan, en la época de Miró y aun hoy en día, al menos subconscientemente, algunas facetas de la «convivencia» medieval de las tres leyes.

Sin lugar a duda, Miró ubica Figuras en Tierra Santa y no viste a españoles «modernos» de judíos y romanos sólo para (re)poblarla. De tal modo, el novelista insinúa una conciencia más «hebrea» que «griega» del tiempo, el que en su novela encuadra y se incorpora a una unidad indivisible, que es el presente, aunque simultáneamente contiene el pasado y el futuro. De cada evento o contingencia podría extraerse una multiplicidad de sentidos inherentes, ya que cada suceso viene cargado de posibles reverberaciones, referencias y patrones de identidad que se extienden infinitamente. Tal coeficiente temporal figura como elemento fundamental de la perspectiva midrashista (ver Handelman págs. 36-37; Boman 123-183; Gould 5-6, 11-12 et passim). Vemos en la novela de Miró una serie, a primera vista casual, casi fortuita, de retrospecciones y de anticipaciones, de múltiples puntos de vista y de hilos narrativos que a veces parecen medio caóticos, pero que no lo son. Quizá tales elementos se configuren como tiempos más bien ceremoniales, si no precisamente atemporales, que van girando en torno suyo de nuevo, cada vez que la historia sagrada se narra, o cuando se celebra la misa u otro culto. A propósito, Handelman trata de cierta conciencia temporal, donde los eventos del pasado y sus consecuencias están continuamente presentes en el subconsciente. Por su parte, Miró narra más bien a lo hebreo, sin centrarse en lo estrictamente lineal, sino reconociendo las múltiples tangentes posibles, amén del lirismo latente que se presenta en cada instante. Infunde tal conciencia hebrea (y regularmente freudiana) en sus personajes, como en sus mismos lectores. Vemos esta consustancialidad, o al menos una suerte de contemporaneidad, en sus obras como Figuras, donde existe un continuum entre los tiempos y los lugares de ayer y de hoy, del acá y del allá. Es una Tierra Santa sempiterna, tanto en Palestina, como en Sefarad (o sea, en Iberia), en el siglo Xx, igual que en el I. ${ }^{6}$

Para Miró, a pesar de edictos, estatutos y expulsiones, el espíritu del hebraísmo todavía se mueve sobre la faz de la Península Ibérica, lo que va más allá de la «afinidad judaica» que le atribuye su amigo Ricardo Baeza (pág.

6. Handelman estudia en detalle a Freud, a quien pinta como «rabino laico», y el psicoanálisis (págs. 36, 129-52). La controversia en torno a Miró, el psicoanálisis y lo freudiano se resume en Larsen 1997, págs. 197-98, 202-27. En cuanto a la importancia de la «contemporaneidad» para entender históricamente la cristiandad, Boman escribe que para Sören Kierkegaard, el filósofo danés que tanto influyó en Unamuno, «to be a true Christian and truly to believe in Christ means ... to leap across and forget the centuries in order to become contemporaneous with Jesus and his disciples as well as his opponents, to see and hear the simple, misunderstood Rabbi ... The idea of contemporaneity, says Kierkegaard ... 'is for me the thought of my life'» (147-48). 
xviii). Es decir, las cuestiones de ascendencia y de raza, de limpieza y de inquisición, siguen vigentes en el subconsciente español, según señalan figuras preeminentes del hispanismo como Américo Castro, Julio Caro Baroja y Francisco Márquez Villanueva. Cabe recordar que Miró mismo ha experimentado algunos de los rigores, si no la plena furia, del parecer inquisitorial, cuando se publicó en Gijón (1917) un fragmento de Figuras. Sin duda, Miró localiza su versión de la Pasión de Jesús en el primer tercio del primer siglo cristiano, pero a la vez indica aspectos de la pasión nacional. Hay que entender Figuras en su propio entorno, esto es, en los albores del cristianismo, ya que va constituyéndose, a veces a duras penas, del fermento cultural que entendemos hoy como el judaísmo rabínico y formativo, a diferencia del normativo de hoy. Sin embargo, Miró presenta su poesis según paradigmas que de buena gana reconocemos como hispanos y contemporáneos nuestros.

Jacob Neusner, el eminente estudioso de todo lo judaico, explica que desde los tiempos más tempranos a las épocas más recientes, el judaísmo sigue existiendo en la matriz del cristianismo y que ambas tradiciones se influyen mutuamente (ver Judaism in the Matrix of Christianity). Según la narrativa mironiana, tal condición de judaísmo se encuentra también penetrada de la historia más «moderna». Una obra como Figuras no puede dejar de evocar un aura algo anacrónica, en parte por lo que sabemos de la Pasión por la Biblia y por todas las historias derivadas de ella, las cuales siguen representándose a través de los siglos. Miró reconoce esta realidad, reiterando al final de Lo viejo $y$ lo santo en manos de ahora algunos corolarios de su midrash:

Este libro de Figuras de la Pasión y los que pueda ir labrando de la cantera eternal del Antiguo y del Nuevo Testamento -con asuntos tan decaídos para algunos pareceres- tienen su principio y mantenimiento en nuestra infancia, un origen y un sostén fervoroso de ingenuidad; pero es que sus evocaciones se hallan impregnadas de nuestra emoción de la Semana Santa, de su liturgia magna y triste, y de la lírica de nuestra mocedad (págs. 316-17).

Otro leitmotiv de Figuras se centra en la temática hispana, a saber, en la limpieza de sangre y la ascendencia «racial». En la novela, la vida de las gentes de la Palestina del siglo I se realiza como otra «edad conflictiva», según la frase tan apta de Américo Castro para describir los siglos áureos de Iberia. Judas Iscariote queda como hombre de su propia época, pero su lamento «iQué tengo yo en mi sangre para que me aborrezcan!» va más allá de sólo una queja por la falta de respeto que siente al compararse con Juan y Simón (pág. 1.241). Más tarde, Miró imagina a este mismo Judas en términos igualmente sanguíneos: «se sentía tan humillado, que le pareció que las sandalias de todos le pisaban en la sangre» (pág. 1.242). Luego «la sangre del de Kerioth criaba como un 
humo de desgracia y de aborrecimiento» (pág. 1.250); y al enterarse de que Jesús ya sabía lo que pensaba hacer, «Judas sentía todo el recinto herido por el latir de sus arterias» (pág. 1.252). A través de los siglos, este personaje se ha visto cargado de una multitud de conotaciones peyorativas a causa de su traición. De acuerdo con la tradición folklórica, si no la eclesiástica, Miró pinta al discípulo fementido como pelirojo (pág. 1.235), indicando quizá su tendencia sangrienta, al igual que el mal agüero, que informa su suerte. En suma, el novelista hace destacar en Judas su superable calidad como «forastero», aun en su propia tierra. Judas insiste varias veces en que es «judío, judío», pero de todos modos le acusan de renegar «de la tierra, y es tierra de los patriarcas, tierra de Israel, prometida por Dios» (pág. 1.237).

Tal double jeopardy recuerda la condición de los conversos, quienes sufren como víctimas y victimarios por su doble traición. A causa de su «deslealtad», en primer lugar como judíos renegados y luego como neocristianos judaizantes, son sospechosos, si no expresamente perseguidos y rechazados, tanto por los de la antigua ley, como por los de la nueva. Además, en su vida andariega e inquieta, Judas se encuentra dibujado en la tradición cristiana de acuerdo con el tipo del judío errante, el perpetuo exiliado dentro de su propio país y fuera de él (ver Anderson). Las palabras del Maestro, «iJudas, Judas, aún padeces por mí!» (pág. 1.250), resuenan a lo largo de los siglos en él y en sus descendientes. Asimismo, Jesús también trae a las mientes el caso de los sefarditas, quienes vivían a la misma vez como traidores y traicionados. Algunos de ellos fueron expulsados de su tierra natal, mientras que otros permanecieron en ella. Ya sean éstos o anusim (forzados) o meshumadim (voluntarios), por más que se esfuercen, jamás se escapan de la «mancha» de su pasado étnico y religioso que se mantiene siempre presente. Per saecula saeculorum serán «the other within» (ver Yovel), peregrinos en su propia patria, «strangers in a strange land» (según la nutrida frase de Heinlein).

Al tratar de cuestiones de linaje ya corrientes en la Palestina de la época de Jesús, Miró evoca a la vez todas las tormentosas imágenes asociadadas con la limpieza sanguínea en la Iberia «moderna». Los primeros Estatutos de Limpieza de Sangre se efectúan en Toledo en 1449. Tal debate pronto se amplifica en un conflicto cultural verdaderamente feroz, dando por fin en el dogma que la mancha de semitismo ni siquiera es borrada por las aguas del bautismo, sino que pervive de generación en generación. En este ciclo de inquisiciones y pogroms, el Judas mironiano se yergue en el judío representativo, perseguido por la culpabilidad y el contagio que le siguen sempiternamente. Más tarde, Miró describe a la chusma que invoca sobre sí y sobre sus descendientes la culpa la muerte del Rábbi Jesús, como es llamado, reafirmando así su persona 
judaica a lo largo de la novela (e.g. pág. 1.357). Desde hace siglos, la gente se ha valido de este pasaje bíblico (S. Mt. 27:25), junto con todas las leyendas y midrashim que han evolucionado en torno suyo, para confirmar el oprobio imborrable de los descendientes de Israel y para perseguirlos por su renuencia en sus creencias y prácticas. ${ }^{7}$ Miró hace hincapié en la envidia que Judas siente hacia Juan, al parecer porque el joven apóstol goza de un grado más amplio del amor del Maestro: otra vez esta mala pasión está ubicada en la sangre (pág. 1.250). Miró hispaniza, y aun cristianiza, el nombre del amado apóstol, igual que los de otras figuras en torno a Jesús. El novelista hace igual con el título de Jesús, cuando la gente lo llama «Cristo», la forma griega del arameo, «Mesías»; en «La conciencia mesiánica en Jesús», reconoce tal posible incongruencia, recordando a los lectores que en esta época "ya Galilea se va poblando de gentiles» y que «el habla greciana se oye tanto como el arameo» (pág. 1.228). A veces Miró utiliza los dos títulos -ambos quieren decir «ungido»- en la misma frase (e.g. pág. 1.240), tal vez como ecumenismo artístico. Pero otras muchas veces se vale de «Señor», uso que remite al hebreo «adonai», lo cual ocurre mucho en la Sagrada Escritura para evitar el uso del nombre y hasta de la palabra Dios.

En estas mismas páginas, Miró narra la ceremonia de lavar los pies, acto preliminar de la Pasión. Como es bien sabido, protesta esta acción Pedro, él cuyo apellido arameo -Kefa- también se utiliza aquí y en otras partes de la novela. Sin embargo, se somete a esta limpieza ceremonial, que no deja de recordar las mikvot (lavamientos) del judaísmo, al igual que los demás discípulos, inclusive Judas el de Kerioth, cuyo nombre el novelista escribe así, de un modo más semita y menos cristianizado. El principal apóstol, «encrespado de una humildad hirsuta» (pág. 1.250), se pone a vociferar con los demás contertulianos «iyo quiero ser limpio!» (pág. 1.250). El siempre impetuoso pescador jamás imagina que pronto va a desamparar a su querido Maestro. Pero una vez arrepentido, este Kefa llegará a ser Pedro de verdad, el Pontifex Maximus de la naciente iglesia. Tales descripciones ponen de relieve el hecho de que todos los apóstoles -estos santos, mártires y fundadores de la iglesia-son fieles judíos, creyentes y cumplidores. La traición urdida por Judas a lo mejor resulta mucho más severa, y por consiguiente imperdonable, que el abandono de Jesús por Pedro. Esta piedra por venir, una vez que se haya «vuelto», o sea, cuando se haya convertido (S. Lc. 22: 31-32), se hace la roca sobre la cual el Nazareno edifica su iglesia (S. Mt. 16:18). Pero en este momento se revela

7. Sobre esto, ver Crossan (1996), quien se dedica, según el subtítulo de su tomo, a exponer las raíces del antisemitismo en las historias evangélicas de la muerte de Jesús. 
más bien como «piedra de tropiezo, y roca que hace caer» (1 Ped. 2:8), esto es, como un ser sumamente falible. ${ }^{8}$ Luego, sobre sus discípulos, incluyendo a Pedro y Judas, Jesús pronuncia esta bendición algo equívoca: « ¡Limpios estáis; pero no todos!» (pág. 1.250), cuyo importe irónico queda patente y aun se aumenta al recordar que los curas y otros fieles cristianos, proclamándose servidores de este mismo Jesús, abogan por la eterna imposibilidad de borrar la mancha semita.

Vale fijarse aquí en otra faceta igualmente irónica de la bendición de Jesús: Miró no cita directamente a San Juan Evangelista, quien deduce a posteriori los pensamientos de Jesús, sugiriendo que éste aludía así a Judas, quien le iba a traicionar (S. Jn. 13:10). El autor de Figuras parece haber decidido no incluir tal detalle redactor, lo cual funciona como midrash por exclusión, indicando quizá parametros aun más amplios de su propia percepción de la Pasión. Miró describe al Señor «volviendo un poco la mirada» y luego añadiendo, «con palabras del salmista: ' Conmigo parte el pan el que ha levantado su calcañar para derribarme!'» (pág. 1.250). Aquí, como en otros muchos momentos de su ministerio, y hasta en sus últimos suspiros en la cruz, donde cita las primeras palabras del salmo 22, Jesús mismo ejerce de midrashista, al hacer su propia exégesis del Salmo 41:9. Extrae el versículo de su contexto originalmente davídico, para indicar su coherencia con la experiencia «moderna». Tal retoque del evangelista, que francamente figura como proof text, infunde a Jesús otro aspecto profético. Mientras tanto, se condena al traidor por venir y a todos los israelitas presentes y venideros a un eterno retorno de delito y vergüenza, sólo «para que se cumpla la Escritura» (S. Jn. 13:10). Al mismo Judas, el Señor le dice: «Lo que hayas de hacer, hazlo pronto» (pág. 1.253; cf. S. Jn. 13:27), pero nótese que Miró omite el juicio condenatorio del evangelista. La forma indicativa del verbo aparece en la Biblia, tanto en la castellana de Casiodoro de Reina, como en la griega y la Vulgata, pero en Figuras, Miró utiliza el subjuntivo, lo que revela una absoluta falta de compulsión, indicando que existe la posibilidad del perdón para el traidor, si lo aceptara. El «nuevo mandamiento» que Jesús sigue predicando al fin es « ¡Amaos, amaos, como yo os amé!» (pág. 1.254). En casi todo el corpus literario de Miró se da casi universalmente el lema «falta amor», pero no con el Nazareno, en quien se encarnan la caridad y el perdón. A la luz de tan fuerte contraste, parece que Miró se acorda bien con el aforismo nietzscheano: el único cristiano murió en la cruz (Der Antichrist, 1895), mientras que la mayoría de los supues-

8. Cito a lo largo del trabajo por La Santa Biblia, publicada por las Sociedades Bíblicas en América Latina (1960), por la antigua versión de Casiodoro de Reina (1569), revisada por Cipriano de Valera (1602), con otras revisiones de 1862, 1909 y 1960. 
tos ministros de su mensaje, tanto los antiguos como los modernos, lo han malentendido, menospreciado y mofado.

La letra del midrash mironiano cumple con el espíritu del Evangelio: retrata a un Mesías misericordioso, nada severo ni justiciero. Jesús se siente entristecido al punto de la muerte, «acechado por aborrecimiento» (pág. 1.255), pero simplemente no sabe condenar a nadie. Lo expresa bien Josef de Arimathea, uno de los «sanhedritas amigos de Jesús»: «iLe odian porque pudo perdonar!» (pág. 1.389). Este mismo viejo califica la compenetración

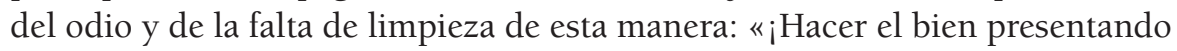
el alma limpia es acercar demasiado la lámpara a las vilezas de los otros!» (pág. 1.389). Tal uso de «limpia» es otro ejemplo que podemos esgrimir en el contexto de la limpieza de sangre: la de Jesús, éste tan limpio como un niño, limpia a todos los que quieren ser limpios, mientras que los no limpios proyectan su propia suciedad en él y en su séquito. Puede que exista aquí otra resonancia de la Sagrada Escritura, ésta de un incidente que tiene lugar después del inicio de la Pasión de Cristo. El apóstol principal, convirtiéndose en la piedra prefigurada por su apellido, experimenta una visión en la que aprende: «Lo que Dios limpió, no lo llames tú común» (He. 10:15; 11:9). Explica que antes era «abominable» que «un varón judío» se juntara «a un extranjero», pero que «ha mostrado Dios que a ningún hombre llame común o inmundo» (He. 10:28). Luego, afirma San Pablo, otro apóstol de la tolerancia y la inclusión: «Todas las cosas son puras para los puros, mas para los corrompidos e incrédulos nada les es puro; pues hasta su mente y su conciencia están corrompidas» (Tito 1:15). Lo que significa una lección más, tanto para los protoinquisidores de Figuras, como para los oficiales de cualquier Santo Oficio venidero.

Miró presenta a Judas como encarnación de la falta de amor, según se manifiesta en su soledad auto-impuesta y miseria de extranjero. El de Kerioth exclama: «¡Soy como el perro que busca al amo!» (pág. 1.241), recordando a los judíos peninsulares que quedan como canes en busca de quién los acoja, ya que al abandonar una fe, la otra no los recibe. Tal imagen de perros, cargada de la nutrida ironía mironiana, repercute también en la descripción de la muchedumbre. Este gentío, animado por sus sacerdotes, pide la muerte de Jesús: "ya todos rugían la maldición con un ahínco que les rasgaba las bocas y les inflaba las fauces como gañiles de perro» (pág. 1.357). Tal símil canino da lugar a un sinfín de asociaciones peyorativas, puesto que los semitas hispanos y sus descendientes neocristianos se veían caracterizados como «perros» (Herrero García pág. 636). Pero por igual parte, los perseguidores se caracterizaban como perros. Por ejemplo, el habla popular nombraba a los 
frailes de la Orden de Santo Domingo, los Dominicos, como «domini canes», perros del Señor que se dedicaban con ferocidad a la persecución de herejías (ver Reston, Jr.). Por medio de tales imágenes, vemos una y otra vez cómo se insinúa un Levante en otro. Asimismo, el novelista jamás nos permite olvidar que Jesús mismo es un judío. Valiéndose del estilo indirecto libre, describe la entrevista entre Pilato y Jesús: «se miraron. Y parecióle a Poncio que resalían en el Rábbi los rasgos firmes, angulosos, de terquedad y sigilo de la raza odiada» (pág. 1.349). Aun delante del romano, el Señor prosigue su midrash.

Tal como acaba de hacer con sus discípulos en esta misma Pascua, donde encontramos un pleno uso de «los salmos del rito» (pág. 1.251), Jesús ejerce de «padre de familias» (título de esta misma sección de la novela, págs. 1.24458), recordando el concepto romano de paterfamilias, al igual que el papel explícitamente dictado para el varón principal de cada unidad familiar entre los hebreos (ver Donin págs. 229-36). Puede que en estas páginas Miró peque de anacrónico, empleando el nombre cristianizado de Santiago, ya que la santidad, la consagración pública y oficial por la iglesia, todavía no existía. Sin embargo, la imagen de «los creyentes como santos» sí que tiene vigencia contemporánea, hasta en los mismos salmos (e.g. 30:4, 34:9, etc.). Prosiguiendo la ceremonia, Jesús y sus discípulos cantan y leen los versículos de Éxodo y de los salmos tradicionalmente asociados con el seder pascual. El novelista ejerce también de midrashista, mencionando que en un punto «todos se alzaron para recitar el Hagada del Deuteronomio» (pág. 1.251). De acuerdo con el sentido de haggadah, Miró hace hincapié en cómo el Maestro «contaba» los eventos del éxodo y después de éste (págs. 1.251-52). El rabí Donin confirma la larga tradición del midrash pascual, cuando asevera que es digno de alabanza que los que están presentes en la ceremonia inyecten sus comentarios, explicaciones e interpretaciones sobre el texto escrito (págs. 233-34). Luego, Jesús instituye la Eucaristía al final de esta Santa Cena. Miró imagina al Cristo invocando que es " $i[\mathrm{su}]$ sangre que sella una alianza perdurable entre la tierra y el cielo!'» (pág. 1.255), subrayando de nuevo que la sangre santifica, y que no condena a los creyentes.

Después de beber tal pacto, Miró explica cómo todos los comensales «entonaron el salmo de las alabanzas y aflicciones» (pág. 1.255). Cantan el Salmo 137 (el 136 de la Vulgata): este poema no figura generalmente en las Pascuas, ni en las judías ni en las cristianas, aunque tal uso no contradice el espíritu de la festividad, y de vez en cuando aparece en ceremonias muy innovadoras. De hecho, este salmo resulta revelador, tanto de las tradiciones y trayectorias de la hermenéutica rabínica, como de la mentalidad del autor al incluirlo en su novela. Cabe recordar que la ceremonia del seder todavía iba evolucionando 
durante el primer siglo de nuestra era. Los estudiosos se hallan divididos aún con respecto a la calidad de la Última Cena como seder. El mismo San Juan, autor del único evangelio no sinóptico, no concuerda con los otros tres evangelistas, sino que afirma una cronología que a fin de cuentas imposibilita que la última comida de Jesús con sus discípulos haya sido un seder pascual. Sin embargo, parece que Miró, en lo tocante a sus descripciones del banquete, coincide con las de los Santos Mateo, Marcos y Lucas. Señala que «el Rábbi bebió de la postrera copa de la vieja Pascua» (pág. 1.253). En su midrash, tanto del seder como de la Santa Cena, vemos a Jesús haciendo brotar lo nuevo de lo viejo. Como punto de referencia, cito aquí los versículos que cita Miró:

¡En las riberas de los ríos de Babilonia nos sentamos llorando, porque pensábamos en ti, Sión!

Colgamos de los sauces nuestras arpas y citaras.

Y los que por fuerza nos llevaban, dijeron:

Cantadnos canciones de vuestra patria y de vuestro Dios.

¿Cómo cantaremos cánticos del Señor en tierra ajena? (págs. 1.255-56)

Al incluir estas líneas del salmo, Miró retrata a Jesús como exegeta, siempre elaborando e iluminando la tradición textual, extrayéndole nuevos sentidos y al mismo tiempo haciéndola eternamente vigente. Por su parte, el novelista participa en este modo poemático, revelándose una vez más como midrashista nada esquivo en su exégesis. ${ }^{9}$

James L. Kugel enumera la historia interpretiva de este salmo, señalando que cobró un sentido especial a finales del primer siglo de nuestra era, después de la detrucción del Segundo Templo. Asimismo Kugel confirma la envergadura de este evento, que los intérpretes asociaban con la destrucción del Primer Templo y el Cautiverio Babilónico, sucesos que ocurrieron durante el sexto siglo antes de nuestra época y que a su vez fueron elaborados en el salmo (págs. 172-213). Algunos escritores aseveran que la destrucción del Templo de Herodes marcó un punto clave en la evolución del seder, porque los sacrificios ya no podían llevarse a cabo en Jerusalén. Tal trauma tendría que reconfigurarse, aunque oblicuamente y por medio de nuevos midrashim,

9. Primero, quisiera expresar mi sincero agradecimiento a mi colega y amigo, el Dr. Seth Ward, quien en lo tocante a las Pascuas tradicionales de la comunidad judáica, me ha ayudado muchísimo. Además, el tomo de Donin es una guía sumamente útil sobre las preparaciones y luego sobre las ceremonias del seder (págs. 218-38). Sobre aspectos evolucionarios del seder, así como sobre la comparación del seder y la Pascua cristiana, en especial cuando están contextualizados con el Salmo 137/136, ver Bokser págs. 24-33; Klawans págs. 24-33, 47; Benedicto XVI; Miller; Sublett. Sobre la haggadah del seder, que hoy en día registra gran variedad de contenido y de estilo narrativo, ver Klawans págs. 30-31. 
proponiendo una profecía davídica que pronosticara tanto la primera como la segunda pérdida de su simbólico centro cúltico de la nación (ver Bokser págs. 28-31, y Klawans págs. 31-33, 47). Miró desarrolla imágenes paralelas de los asistentes a la Cena, quienes cantan este salmo de exilio a priori y ex post facto. La pasión de los descendientes de Jacob se involucra en el pasado, en el presente y en los futuros posibles: existen por supuesto muchos nexos y niveles de interpretación, de midrash sobre midrash, al tanto de las prácticas rabínicas, quienes a su vez ejercían de novelistas de la Sagrada Escritura. Kugel menciona otro detalle de la extensión del salmo, que la crucifixión figuraba tradicionalmente entre los sufrimientos de los cautivos hebreos (págs. 193, 212), lo que acaso revele otra faceta aun de la poesis que se arma en Figuras.

Se escuchan ecos del mismo salmo 137, al igual que de otros textos sagrados, en la condenación de Jesús por Pilato, secundada por el vocerío de la multitud. Al lavarse las manos, rechazando cualquier complicidad con la sangre del Justo, el Procurador recuerda el lavamiento de pies recién llevado a cabo. De hecho, este romano da sin saberlo en una serie de midrashim sobre las abluciones. Miró señala algunas de las corrientes de tal chorro intertextual, describiendo cómo el romano «tendió sus brazos, y el agua goteó en la cabeza lacia de Cristo»:

Y Jerusalén temió. Un gentil evocaba la voz del salmista: «Lavaré mis manos entre los inocentes»; y la solemne severidad del Deuteronomio: «Cuando fuere hallado un hombre muerto, y no se supiere quién le mató, saldrán los ancianos de la Judicatura y medirán la tierra desde el sitio del cadáver hasta las ciudades del contorno; y los jueces del lugar más inmediato tomarán un ternera añoja que no haya traído yugo ni roto el campo con la reja; y llevándola a un valle árido, le quebrarán la cerviz. Y los ancianos lavarán sus manos sobre la res, diciendo: 'Nuestras manos no derramaron la sangre de ese hombre ni nuestros ojos lo vieron. ¡Sé propicio, Señor, a tu pueblo, a quien rescataste, y no le imputes la sangre inocente!' Y será apartado de los jueces el reato y peso del homicidio.» Y la Glosa de Sôtah resume y cifra el texto mosaico: «Tan puras y limpias como nuestra manos lustradas, están nuestras conciencias de toda sangre.» (pág. 1.357)

En este retrato de los sacerdotes y la gente laica de Israel, ya condenados por haber condenado al que pensaba librarlos de sí mismos, Miró encuadra las múltiples ironías sugeridas por el salmo de la pasión nacional, abarcando en él todo su agobio y oprobio, toda su renuencia y ressentiment.

A su vez, Marcel Bataillon propone el salmo 137 como tábula de «la multisecular herencia de melancolía del pueblo judío, criado en la amargura del destierro; pues tan desterrados se sentían los judíos, desde la diáspora, como sus antepasados que lloraban a orillas de los ríos de Babilonia» (pág. 40). Este 
distinguido hispanista francés nota ciertas posibles resonancias del salmo 137 para con los cristianos nuevos de Iberia. Sin nombrarlo así, Bataillon entiende «la sensiblidad neo-cristiana» como otro midrash de este salmo, resumiendo en una forma tradicional toda la «desazón» y «melancolía» (pág. 40) de los doblemente exiliados. Su nuevo cautiverio babilónico es vigilado por el Santo Oficio. Otros críticos también han comentado el refundir el salmo, desde el Renacimiento hasta nuestros tiempos, recordando que existían otras muchas versiones de él en las literaturas nacionales de Europa, con muchos destacados ejemplos que aparecen en las literaturas castellana y lusitana. Excelsos artistas literarios como Milton, Shakespeare, Camões, Montemayor, Fray Luis de León y San Juan de la Cruz, quienes no necesariamente eran ni judíos ni judeoconversos, enseñan así su solidaridad con la «nación» perseguida, ofreciendo midrashim de simpatía por el sufrimiento. Existe además en sus obras el reconocimiento de la universalidad de las imágenes y los sentimientos expresados por el salmista, los que repercuten en todas las culturas, promoviendo entre sí una continuidad literaria en la que Miró participa. ${ }^{10}$

Miró se esfuerza por presentar a los hebreos de su novela como gente de su propia época. No son cristianos de los inicios del siglo Xx, figiéndose judíos y demostrando, por lo terca de su persona, la veracidad del dogma cristiano. Pero no por ello dejan de recordar los personajes mironianos a los judíos sefarditas de edades más tardías, tal como los escribas y los fariseos, igual que Kaifás, Anás y los de su compañía sacerdotal, traen a las mientes los inquisidores, especialmente cuando se tiene en cuenta su mutua preocupación por la pureza del linaje (ver págs. 1.260; 1.291; 1.305-7; 1.370-71; 1.391-92 et passim). Cabe decir que los perseguidores de cualquier época se difieren muy poco entre sí. En Figuras, se encuentran yuxtapuestos todos con sus pares, girando en una ronda perpetua de intolerancia y de falta de amor. No es que su Jerusalén sea explícitamente el Toledo ni el Valladolid a lo Guevara. Pero en «Lo viejo y lo santo en manos de ahora» Miró recalca que existen resabios de lo contemporáneo en la narración del pasado: en su novela, «las evocaciones se hallan impregnadas de nuestra emoción de la Semana Santa, de su liturgia magna y triste, y de la lírica de nuestra mocedad». Luego, cita a otro que se distinguió como midrashista, André Gide, afirmando que «el Arte, aunque le

10. Entre otros muchos estudios del salmo 137 en la literatura europea del Renacimiento hasta el siglo XX, ver Fernández de Castro; Bataillon págs. 39-54; Blecua págs.113-26; Creel; Di Mauro págs. 5-7; Giudicelli págs. 255-63; Hamlin págs. 224-57; Picchio págs. 559-99. 
lleguen reflejos del Cielo, es una cosa enteramente humana» (págs. 316-17). ${ }^{11}$ El ciclo de los midrashim, al parecer atemporal, si no explícitamente eterno, es la interpretación libre y lírica de la Sagrada Escritura. Según las casi infinitas posibilidades que se presenten, florece como un arte al parecer promovido por el Cielo. Pero sigue en pleno contacto con la tierra y en función con sus moradores demasiado humanos.

En este contexto, Figuras de la Pasión del Señor tiene un paralelismo con la obrita de Dostoyevky La leyenda de Gran Inquisidor, intercalada como sueño en Los hermanos Karamazov (1879-80). El novelista ruso enumera las reacciones ante Cristo que, vuelto a la tierra, ha estado predicando en la Sevilla del siglo XVI, y luego es prendido para comparecer delante del jefe del Santo Oficio. Su nueva Pasión, igual que la del Gran Inquisidor, recuerdan las de los sumos sacerdotes de la Biblia, al lado de los que Miró engrana en su propia novelística. Los prepotentes eclesiásticos que describe quedan como figuras en los albores de nuestra era, pero no dejan de suscitar una simbiosis de lo antiguo y lo moderno. Mientras tanto, Jesús se yergue en el «Servidor que sufre» (Is. 53), una imagen que resuena con las de todas las personas procesadas y martirizadas por la Inquisición. Estas víctimas venideras se recapitulan recíprocamente en el primer cristiano, cuyo mensaje de misericordia parece que sigue siendo rechazado por los órganos oficiales en cualquier edad del mundo. Los sacerdotes principales de su época, igual que los de la España que describe Dostoyevsky, consideran al Nazareno como un gran hereje, uno cuya existencia en el mundo perjudica mucho a los de su nación y de su religión, tramitando en sí una tremenda amenaza a su jerarquía de poderes y privilegios. Lo mismo pasa con los marranos, los moriscos, los luteranos y los demás apóstatas de los siglos venideros; pervive así la Pasión Divina en las tribulaciones de todos los que vendrán después. Al final de la novela, la mujer samaritana se queja: « ¡Rábbi, Rábbi! ¿Por qué has resucitado para subirte al cielo?» (pág. 1.400). En sus palabras tan cargadas de esperanza y de tristeza reverberan todas las expectativas y añoranzas, las que vemos surtidas en todas las edades y por todas las leyes. Los discípulos siguen proclamando la buena noticia, que «Jesús ha rescucitado, y subió al cielo» (pág. 1.400). Pero su Pasión está proyectada en los sufrimientos de los que se quedan en la tierra, sean éstos judíos, cristianos, paganos o lo que fuesen. Tal nexo de imágenes resulta

11. Dos figuras contemporáneas suyas que influyeron mucho en Miró, André Gide y Oscar Wilde, a su vez programaron su «perverse midrash» (Downey). Ver también: Macdonald 1975, págs. 32, 151 et passim, y 2002, pág. 91; Larsen 1989, págs. 69-89. 
ser como un espejo, una mise-en-abîme donde cobran forma y se reflejan entre sí una legión de los posibles midrashim. ${ }^{12}$

Miró señala también cómo los enemigos del Rábbi «ya malsinan de él y tuercen sus intenciones» (pág. 1.273). La palabra malsín, que viene originalmente del hebreo y quiere decir calumniador, aparece en catalán al menos hacia 1327, y más tarde, hacia 1530, entra en el castellano (Lourie págs. 85, 87). Esta historiadora afirma que el ser malsín de otro de su propia ley era una de las peores ofensas que un judío podría cometer (Lourie págs. 69-102). Desgraciadamente, el ser malsín pasa del call sefardita a los consejos del Santo Oficio, llegando tal denuncia o tacha casi siempre anónima a ser una preferida táctica de terror. Surtía una violencia íntimamente familiar, en la cual tanto el malsín como el delatado sufrían en extremo: así seguían siendo divididas, si no rajadas, las familias, las comunidades y las naciones. En Figuras, encontramos a una gente autófaga, que se consume en el odio a sí misma, anticipando lo que Sander Gilman más tarde caracteriza como el «auto-odio judío» (ver Jewish Self-Hatred). Lo que no quiere decir que Miró fuera antisemita. De hecho, puede que en su visión del pueblo esparcido de Israel el novelista vislumbre una nación cristiana relativamente nueva y de la época más bien reciente. España por su parte sigue consumiéndose, como un Saturno redivivo que devora a sus propios hijos «heterodoxos». Para los de la supuesta mayoría, estos grupos ajenos son el «otro», pero sin dejar de ser de la propia carne de los que los acosan. Tales midrashim se presentan como esperpentos, en vez de resabios áureos de once and future glory.

Miró insiste en pasar su poesis por este mismo prisma, desmitificando el pasado para poder crear el presente. Valiéndose de nuevo del estilo indirecto libre para comunicar el odio verdaderamente visceral de Pilato contra todo lo semita, Miró afirma que «Poncio odió a Israel hasta por la náusea del suplicio. Sentíase murado de padecimientos» (pág. 1.324). Pero no es por haberse hastiado de hacer matar a tantos otros judíos, por lo que piensa dejar libre al Rábbi. El romano dice a su mujer, Claudia, la que según la tradición ha soñado con Jesús y se esfuerza por protegerlo delante de su marido: «¡Amiga mía: Israel nos acecha! Es la fiera del desierto que no sabe obedecer ni mandar.» (pág. 1.325). Luego, otra descripción acertada: «Poncio, pálido de repugnancia y odio, se recoge a su cámara», mientras que fuera de su palacio se multiplican los midrashim: «se arrastran los salmos alaridos del pueblo. Sobre los cadáveres aplastados avanzan y se renuevan los judíos, vestidos de

12. La posible asociación entre el midrash y las reflexiones (o refracciones) en el espejo recuerda la novela de Wilde, The Picture of Dorian Gray (1890). 
penitencia, que lloran el despojo sacrílego, sin mirar el brazo que les aguarda para herirles. Es la obstinación del semita, que agota la rabia del amo» (pág. 1.327). Son palabras que encierran en sí todo el encono y toda la frustración de la Iglesia, viendo fracasados sus planes de convertir a los judíos.

El gran error de los perseguidores en todas las épocas de la historia ha sido el negar la voluntad del ser humano, esperando que, con la humillación de la carne, alguna vez se domine, si no se convierta, al espíritu. Miró vierte luz sobre lo que podemos llamar un continuum de contiendas, las que se luchan en el Imperio Hispánico (y cristiano), igual que en el Imperio Romano: «Entre el Procurador y las gentes judías ya sólo queda un mundo de furor implacable y una humillación rencorosa»; habla de cómo a sus espaldas los impotentes rodean a su gobernador «de un silencio miedoso, de sonrisas frías, de miradas oblicuas». A propósito de esta posible conexión hispana, Miró cita «una historia ruin» que «se ha difundido por Jerusalén»: «Poncio Pilato es liberto de un soldado de Iberia... Sirvió a Roma con deslealtad para los suyos; medró con delaciones.» Hablan de Claudia y de cómo ha conseguido «el favor de Tiberio», y corren rumores de la absoluta decadencia para infundir la condenación horrorizada, igual que la envidia rencorosa, en los judíos, antes elegidos y ahora gobernados por gentiles tan inmundos. Pilato se venga de tales detractores, valiéndose de técnicas inquisitoriales que más tarde se van a recrudecer en la Iberia de donde dicen que vino: «Los escuchas de Poncio le refieren la difamación y por las noches, en el ergástulo, los lictores amputan con su segur la lengua de los malsines cazados» (pág. 1.327).

Miró logra describir con gran verosimilitud, tanto a los gentiles como a los hebreos, aunque sin nadar en las corrientes del antisemitismo removidas por la Roma imperial e inquisitorial. A propósito, su comentario sobre Sor Ana Catalina Emmerich, autora de La dolorosa pasión de nuestro Señor Jesucristo (1833), que tal vez influyera en el alegado prejuicio antisemita de la película de Mel Gibson, La Pasión del Cristo (2004). ${ }^{13}$ En «Lo viejo y lo santo en manos de ahora», Miró menciona a esta monja y su obra, diagnosticando en ellas algo que no quería verter en su Pasión:

Todas sus páginas tienen la misma prolijidad, exactitud arbitraria, alucinatoria; es decir, a su arbitrio de iluminada reverencia. Lente magnífica para mirar, demasiado cerca, pueril, confuso y transido, el corazón de Sor Ana Catalina que no evoca, sino que registra sus imágenes de dolor; su propio dolor hecho carne divina. Primitivismo, tal vez sin gracia de los primitivos, con abrasada caridad. Lo santo en manos santas, lisas y maceradas (pág. 302).

13. Ver una entrevista a Gibson, citada por Crossan 2004, págs. 11-12.

Anales, 22, 2010, pp. 145-170 
A despecho de tales prejuicios, Sor Ana Catalina ofrece algo que podemos entender como su propio midrash de los sufrimientos de Jesucristo. Por obvias razones Miró rechaza tal interpretación, no por ser tan primitiva, sino por andar demasiado apartada del espíritu y la letra de los acontecimientos en cuestión. Por su parte, el novelista procura recuperar tal espíritu y mantenerse fiel a la letra. Al tratar de la monja y su obra, Miró ilumina mucho su propia trayectoria en Figuras: componer un midrash, una obra de arte poético fiel en sí y fiel a la Sagrada Escritura, no algo falso, como cree haber encontrado en Emmerich.

Mientras tanto, pasando por el Nazarín galdosiano (1895), entre otras obras de escritores novecentistas, y contando con figuras de tanto relieve como Schweitzer, Silone, Unamuno, Steinbeck, Kazantzakis, Faulkner, Greene y Vidal, y prosiguiendo hasta los tomos de Jim Bishop, John Dominic Crossan, Paula Fredriksen, Luke Timothy Johnson y Raymond E. Brown, entre otros muchos, no cabe duda que existe un movimiento para reconfigurar al Jesús «histórico». En Figuras, Miró logra dominar un torrente de textos cristológicos, éstos muchas veces apasionados en sí y entre sí, tanto en lo literario como en lo histórico y lo teológico, y todos dedicados según su propia visión a reconstituir o a reimaginar la Pasión del Señor. ${ }^{14}$ Miró trata hábilmente con diversas figuras de un pasado que en sus manos jamás resulta remoto. Hablando de Guevara y Monte Calvario, ésta es una obra que Márquez Villanueva categoriza como no tomada, en el fondo, muy en serio ni como materia edificante, sino leída por sus contemporáneos más bien como entretenimiento y/o como diversión. Este dedicado crítico afirma lo siguiente: «El triste sino de Miró y sus Figuras [...] obra respetuosa y no exenta de unción, se viene a las mientes como contraste y como abono de que cualquiera tiempo pasado fue mejor» (1968, págs. 46-47). En su poesis Miró profundiza mucho en su materia, definiéndose por su inmenso respeto y destreza como artista y como creyente.

14. Sobre las «transfiguraciones» de Jesús en los siglos XIX y XX, ver Ziolkowki, aunque este estudioso de primera fila no menciona a don Gabriel. Por su parte, el mismo Dr. Schweitzer escribe sobre algunos de sus comensales cristólogos: «Men who have no qualifications for the task, whose ignorance is nothing less than criminal, who loftily anathematise scientific theology instead of making themselves in some measure acquainted with the researches which it has carried out, feel impelled to write a Life of Jesus in order to set forth their general religious view in a portrait of Jesus which has not the faintest claim to be historical» (citado por Ziolkowski págs. 56-57). Seguro que Miró no cabe dentro de tal categoría, ya que a lo largo de Figuras pone en tela de juicio sus muchos estudios. Además, reconozco aquí lo mucho que me ha ayudado mi amigo y colega, el Dr. Paul Flesher, sobre el «historical Jesus movement». 
Figuras se revela como un tomo devoto que lucha por decir la verdad, en vez de predicar ficciones a lo Sor Ana Catalina, las que en un principio se tienen por «edificantes», pero una vez desenmascaradas, lucen más bien de maceradoras. Por supuesto, existen muchos lectores a quienes los libros de la monja les parecen ser otro evangelio: al revisar este trabajo, yo busqué ejemplos de propagandas en el Internet, encontrando una que reza de este estilo: «Profecías y revelaciones asombrosas sobre todo aspecto de la Fe. Edificante en extremo, hace que los Evangelios cobren vida con detalles que Ud. jamás haya conocido con anterioridad» (ver http://www.tanbooks.com). ${ }^{15} \mathrm{~A}$ lo mejor tales elementos «animadores» no se han conocido antes porque no existen, ni en espíritu, en los evangelios. Francamente, Miró ha puesto en evidencia su propia espiritualidad, apoyada por su gran respeto al espíritu que infunde las historias bíblicas, mientras que la Pasión de la beata alemana, una obra según muchos recargada de "aceites devotos», no es nada respetuosa ni respetable, resultando ser más bien histérica que histórica. Ella pinta su propia pasión distorsionada y distraída, en vez de la del Señor. Por lo tanto, Miró la rechaza, aunque no sólo por razones teológicas, sino también por el dolor estético y espiritual que produce. No es que le niegue a Sor Ana Catalina su midrash, o sea, su novela de la Escritura, ya que la Pasión que ella alucina siempre resulta ser una de las casi infinitas posibles. Miró solamente confirma su poco valor poético, que peca de mala poesis. Nuestro novelista de la Sagrada Escritura bien comprende que, por cualquier cala que haga, el exegeta no puede evitar proyectarse en los textos, tanto en los que consulta como fuentes, como en los que se dedica a componer. Según Luke Timothy Johnson, autor de The Real Jesús (1997), cada persona desarrolla su propia representación del Nazareno al contemplarse a sí misma en el espejo, imbuyéndole así al Cristo de los rasgos que ve o que quisiera ver. En Lo viejo y lo santo en manos de ahora Miró afirma que «[e]vocar, reconstruir, no es ilusionarse, no es alucinarse» (pág. 302). Por lo tanto, el novelista dedica su poesis a imaginar a Jesús, escribiendo con un arte que lo ubica ante todo en su propio tiempo. Pero tal proyección parabólica del Hombre-Dios lo hace más asequible, y si fuera posible, más histórico, para los del tiempo de Miró, igual que para nosotros en el nuestro. El novelista logra para sí mismo y para todos sus lectores lo que se propone en su carta a Irles: «mirar de cerca el horizonte cristiano, reconstruyendo lo que no nos decían -igual que lo que nos decían- los textos directos y sagrados». Además, Miró llega a confirmar el paradigma de Johnson, quien afirma que

15. En su inglés original la propaganda reza de este modo: «Prophecies and amazing revelations on every aspect of the Faith. Extremely edifying, makes the Gospels come alive with details you never knew before».

Anales, 22, 2010, pp. 145-170 
es por la literatura, no por la historia, por lo que conocemos mejor al Cristo novotestamentario. ${ }^{16}$

Pasando por estas trayectorias multitemporales, Figuras de la Pasión del Señor recuerda otra novela, una obra de ficción que desde sus primeras páginas insiste en proclamarse nada menos que como una «historia verdadera». Cervantes, otro maestro del midrash de quien Miró ha aprendido mucho, aduce una plétora de posibilidades narratológicas al brindar a través de las generaciones su luciente visión perspectivista. Y, cómo no, en el Quijote repercuten todas las Escrituras, tanto las sagradas como las más bien profanas, y él en ellas. La obra de Cervantes figura preeminentemente como «divina novela», según el criterio unamuniano. Por medio de tal poesis la ficción puede llegar a revelar, aun a ser, si no la verdad, al menos una verdad. Cuenta historias verdaderas inspiradas por una veracidad que va más allá de la mera verosimilitud verbal. Unamuno insiste en las semejanzas entre Nuestro Señor Jesucristo y «nuestro señor Don Quijote», ${ }^{17}$ lo que a cierta luz parece más que un poco altivo y egoísta, amén de una evidente blasfemia. Pero en tal figura de Cristo podemos vislumbrar algo sumamente importante en cuanto al parecer que Unamuno comparte con Cervantes y Miró. Lo que vemos en sus versiones de la historia cristiana es un Mesías como artista. Jesús se esfuerza por cumplir la Sagrada Escritura. De acuerdo con el estilo rabínico (ver Handelman págs. 83-120), continúa las historias, las interpreta en su vida y las prosigue hacia el futuro. Es que tal Cristo va "cabalgando», mientras que carga su cruz, (re) inventándose con cada nueva generación, pero sin dejar de ser quien ha sido desde el principio. De este modo se encuadra la pasión poética del midrashista verdaderamente cristiano y castizo.

\section{BIBLIOGRAFÍA CITADA}

AIROZO, James. 1984. Religion, the Bible and Ideology in the Works of Gabriel Miró. Tesis doctoral de la Universidad de Michigan.

- 1987. «Gabriel Miró, Adolf von Harnack, and the Meaning of Jesus». Romance Quarterly 34, págs. 361-70.

AnDERSON, George K. 1991. The Legend of the Wandering Jew. Hanover, NH, University Press of New England.

16. Al hacer esta redacción, me emocionó mucho una conferencia de Luke Timothy Johnson, titulada «Learning the Human Jesus: Historical or Literary Criticism?», la que se realizó en el campus de la Universidad de Wyoming el 15 de septiembre de 2009.

17. Esta idea y otras similares aparecen a lo largo del corpus literario de Unamuno. Sobre su quijotismo cristiano, ver El Cristo de Unamuno (Madrid, Rialp, 1960), por Vicente Marrero, especialmente las págs. 155-204. 
BAEZA, Ricardo. 1935. «Prosa de Gabriel Miró», prólogo de Figuras de la Pasión del Señor, en Edición Conmemorativa de Obras completas de Gabriel Miró. T. 5. Barcelona, Altés, págs. ix-xxx.

BATAILlON, Marcel. 1964. «¿Melancolía renancentista o melancolía judía?» en Varia lección de clásicos españoles. Madrid: Gredos, págs. 39-54.

Benedicto XVI. «Comentario al salmo 136, 'Junto a los ríos de Babilonia'». «Creyentes y no creyente, peregrinos hacia la Ciudad de Dios». Zenit-El mundo visto desde Roma. http://www.zenit.org/spanish/audiencia/visualizza. phtml?sid=80232

BlECUA, José Manuel. 1988. «Sobre el salmo Super Flumina», en Homenaje a Eugenio Asensio. Madrid, Gredos, págs. 113-26.

BOKSER, Baruch M. 1987. «Was the Last Supper a Passover Seder?» Bible Review, págs. 24-33.

Boman, Thorleif. 1970. Hebrew Thought Compared with Greek. Nueva York/Londres: Norton.

CreEl, Bryant L. 1981. The Religious Poetry of Jorge de Montemayor. Londres, Támesis.

Crossan, John Dominic. 1996. Who Killed Jesus? San Francisco, CA, HarperCollins.

- 2004. «Hymn to a Savage God», en Jesus and Mel Gibson's The Passion of the Christ. Londres/Nueva York, Continuum, págs. 8-27.

Di MAUro, Damon. 1993. «An Imitation of Marot's Psalm 137 in Garnier's Les Juifves». French Studies Bulletin 48, págs. 5-7.

Donin, Hayim Halevy. 1972. To Be a Jew. Nueva York, Basic Books.

Downey, Katherine Brown. 2004. Perverse Midrash. Oscar Wilde, André Gide and the Censorship of Biblical Drama. Nueva York/Londres, Continuum.

FERNÁNDEZ DE CASTRO, Eduardo Felipe. 1928. El salterio de David en la cultura española. Madrid, Imprenta Helénica.

FISHBANE, Michael. 1998. The Exegetical Imagination. Cambridge, MA/Londres, Harvard University Press.

GerTner, M. 1962. «Midrashim in the New Testament». Journal of Semitic Studies 7, págs. 267-92.

GILmAN, Sander L. 1986. Jewish Self-Hatred. Baltimore, MD, Johns Hopkins University Press.

GIUDICELLI, Michelle. 1995. «Super Flumina Babylonis ou la projection dans le miroir», en $O$ Amor das Letras e das Gentes. Santa Barbara, CA, Center for Portuguese Studies, págs. 255-63.

Gould, Stephen Jay. 1987. Time's Arrow, Time's Cycle. Cambridge, MA/Londres, Harvard University Press.

GuillÉn, Jorge. 1969. Lenguaje y poesía. Madrid, Alianza Editorial. 
HamLin, Hannibal. 2002. «Psalm Culture in the English Renaissance: Readings of Psalm 137 by Shakespeare, Spenser, Milton and Others». Renaissance Quarterly 55, págs. 224-57.

Handelman, Susan A. 1982. The Slayers of Moses. Albany, NY, State University Press of New York.

Hartman, Geoffrey H. y Sanford Budick, eds.1986. Midrash and Literature. New Haven, CT, Yale University Press,

Herrero García, Miguel. 1966. Ideas de los españoles del siglo XVII. Madrid, Gredos.

KAHANE, Rabbi Meir. «Passover-Holiday of Vengeance». http://kahane.org/meir/ passover.html.

KIRK, John R. 1976. The Religious Aesthetic of Gabriel Miró. Tesis doctoral de la Universidad de Princeton.

- 1979. "Questions of Originality: The Use of Sources in Figuras de la Pasión del Señor» en Critical Essays on Gabriel Miró. Ann Arbor, MI, Society of Spanish and Spanish-American Studies, págs. 66-83.

KLAWANS, Jonathan. 2001. «Was Jesus' Last Supper a Seder?» Bible Review, págs. 24-33, 47

Kugel, James L. 1994. In Potiphar's House. Cambridge, MA/Londres, Harvard University Press.

LARSEN, Kevin S. 1989. «Decadentismo, dandies y delincuencia: Gabriel Miró y sus retratos de Oscar Wilde,» La Torre (Nueva Época), 3, 9, págs. 69-89.

- 1997. «La ciencia aplicada»: Gabriel Miró y la tradición científica. Madrid, Alpuerto.

LOURIE, Elena. 1988. «Mafiosi and Malsines: Violence, Fear, and Faction in the Jewish Aljamas of Valencia in the Fourteenth Century», en Actas del IV Congreso Internacional «Encuentro de las Tres Culturas». Toledo, Universidad de Tel Aviv/Ayuntamiento de Toledo, págs. 69-102.

LozAno MarCo, Miguel Ángel. 2005. «Gabriel Miró. Del vivir (1904) y su ruptura con la convención novelesca». Revista de Literatura 67, págs. 153-70.

Macdonald, Ian R. 1975. Gabriel Miró: His Private Library and His Literary Background. Londres, Támesis.

- 1990. «The Gospels as Fiction: Gabriel Miró's Figuras and Biblical Scholarship». Forum for Modern Language Studies 26, págs. 49-61.

- 2002. «Figuras de la Pasión del Señor, novela», en Miguel Ángel Lozano Marco, ed., Actas del II Simposio Internacional «Gabriel Miró». Alicante, Caja de Ahorros del Mediterráneo, págs. 81-96.

MÁrQUEZ VILlanUeVA, Francisco. 1968. Espiritualidad y literatura en el siglo XVI. Madrid, Alfaguara. 
- 1990. La esfinge mironiana y otros estudios sobre Gabriel Miró. Alicante, Instituto de Cultura «Juan Gil-Albert».

Miller, Joel. «All Four Sides of the Communion Table-10/7/07-Psalm 137, Habukkuk, Luke 17:5-10, 2 Timothy 1:1-7». http://joelssermons.wordpress. com/2007/10/09/all-four-sides-of-the-communion-table

Miró, Gabriel. 1966. «Lo viejo y lo santo en manos de ahora», en Vicente Ramos. Literatura alicantina (1839-1939). Madrid/Barcelona, Alfaguara, págs. 300-17.

- 1969a. «La conciencia mesiánica en Jesús», en Obras completas. 5 a ed. Madrid, Biblioteca Nueva, págs. 1.225-31.

- 1969b. Figuras de la Pasión del Señor, en Obras completas. Op. cit.: págs. 1.235-1.400.

NeUSNer, Jacob. 1983. Midrash in Context. Atlanta, Scholars Press.

- 1986. Judaism in the Matrix of Christianity. Philadelphia, Fortress Press, 1986.

PicCHIO, Luciana Stegagno. 1984. «Babel et Sion: Inspiration Thématique et Inspiration Formelle dans la Glose Camonienne du Psaume 'Super Flumina Babylonis'», en L'Humanisme Portugais et l'Europe. París, Fondation Calouste Gulbenkian, págs. 559-99.

Prieto de PAula, Ángel L. 2007. «La hipertrofia del yo: Gabriel Miró y la poesía», en Miguel Ángel Lozano Marco, ed., Nuevas perspectivas sobre Gabriel Miró. Alicante, Universidad de Alicante/ Instituto Alicantino de Cultura «Juan GilAlbert»/Diputación Provincial de Alicante, págs. 85-103.

Ramos, Vicente. 1964. El mundo de Gabriel Miró. Madrid, Gredos.

- 1969. «Presentación», en Figuras de la Pasión del Señor. Madrid, Guadarrama, págs. 11-18.

RESTON, JR. James. 2005. Dogs of God. Nueva York, Doubleday.

SAID, Edward. 1978. Orientalism. Nueva York, Random House.

SANDMEL, Samuel. 1961. «The Haggada Within Scripture». Journal of Biblical Literature 80 , págs. 105-22.

SCHWARTZ, Howard. 1998. Reimagining the Bible. Oxford/Nueva York: Oxford University Press.

SublETT, Kenneth. «Psalm 137: Hung Our Harps on the Willows-Jesus Singing Hymns». http://www.piney.com/MuPsalm137.html

Unamuno, Miguel de. 1967. San Manuel Bueno, mártir, en Obras completas. T. 2. Madrid: Escelicer, págs. 1.127-54.

Wright, Addison G. 1967. The Literary Genre Midrash. Staten Island, NY: Society of St. Paul.

Yovel, Yirmiyahu. 2009. The Other Within. Princeton, NJ: Princeton University Press.

ZIOLKOWSKI, Theodore. 1972. Fictional Transfigurations of Jesus. Princeton, NJ: Princeton University Press. 
Fecha de recepción: 2 de septiembre de 2009.

Fecha de aprobación: 12 de noviembre de 2009. 